\title{
Quantitative study of anode microstructure related to SOFC stack degradation
}

\author{
$\underline{\text { A. Faes }}^{1,2}$, A. Hessler-Wyser ${ }^{1}$, D. Presvytes ${ }^{3}$, A. Brisse ${ }^{4}$, C.G. Vayenas ${ }^{3}$ and J. Van \\ herle ${ }^{2}$ \\ 1. Interdisciplinary Centre for Electron Microscopy (CIME), Ecole Polytechnique \\ Fédérale de Lausanne (EPFL), CH-1015 Lausanne, Switzerland \\ 2. Industrial Energy Systems Laboratory (LENI), EPFL, CH-1015 Lausanne, \\ Switzerland \\ 3. Department of Chemical Engineering, Laboratory of Chemical and Electrochemical \\ Processes, University of Patras, GR-26504 Patras, Greece \\ 4. EDF - EIfER, DE-76131 Karlsruhe, Germany
}

antonin.faes@epfl.ch

Keywords: Solid oxide fuel cells, anode degradation, image quantification analysis, TPB

As the performances of Solid Oxide Fuel Cells (SOFC) get attractive, long term degradation becomes the main issue for this technology. Therefore it is essential to localise the origin of degradation and to understand its processes in order to find solutions and improve SOFC durability.

The electrode microstructure ageing, in particular nickel grain coarsening at the anode side, is known to be a major process to cause performance loss [1]. The increase in nickel particle size will diminish the Triple Phase Boundary (TPB), where fuel oxidation takes place, and decrease the anode electronic conductivity. These two effects degrade the electrochemical performance of the fuel electrode.

Degradation is defined as the decrease of potential at constant current density with time in $\% / 1000 \mathrm{~h}$ or $m V / 1000 \mathrm{~h}$. This study is based on HTceramix ${ }^{\circledR}$ anode supported cells tested in stack conditions from 100 to more than 1000 hours.

The anode microstructure has been characterized by Scanning Electron Microscopy (SEM). As the back scattered electron yield coefficients of nickel and yttria stabilized zirconia (YSZ) are very close, the contrast of the different phases (Ni, YSZ and pores) is low. Various techniques are used to enhance the contrast [2,3]. A new technique is presented here using impregnation and SEM observation based on secondary electron yield coefficients to separate the phases.

Image treatment and analysis is done with an in-house Mathematica ${ }^{\circledR}$ code. Image treatment (Figure 1) follows four steps: 1. inhomogeneous background correction, 2. double thresholding, 3 . cleaning of the binary images and 4 . reconstruction of a threephase image. Image analysis gives information about phase proportion, particle size, particle size distribution, contiguity and finally a new procedure is developed to compute TPB density.

A model to describe the coarsening of the nickel particles is also developed. The model assumes an exponential growth of the nickel particles. Using a particle population balance, it estimates the growth of the nickel particles and the concomitant 
drop in the TPB length. This model is in very good agreement with experimental data, especially for relatively low fuel cell operation times (up to 100-200 hours). This model can be used in the estimation of operational parameters of the anode electrode such as the degradation rate using fundamental parameters of the cermet anode like the anode overpotential and the work of adhesion of the nickel particles on the YSZ substrate. This model gives the portion of stack degradation that corresponds to anode performance decrease due to particle sintering.

Finally this study gives the possibility to isolate the degradation coming from the anode sintering and compare to the full SOFC stack degradation.

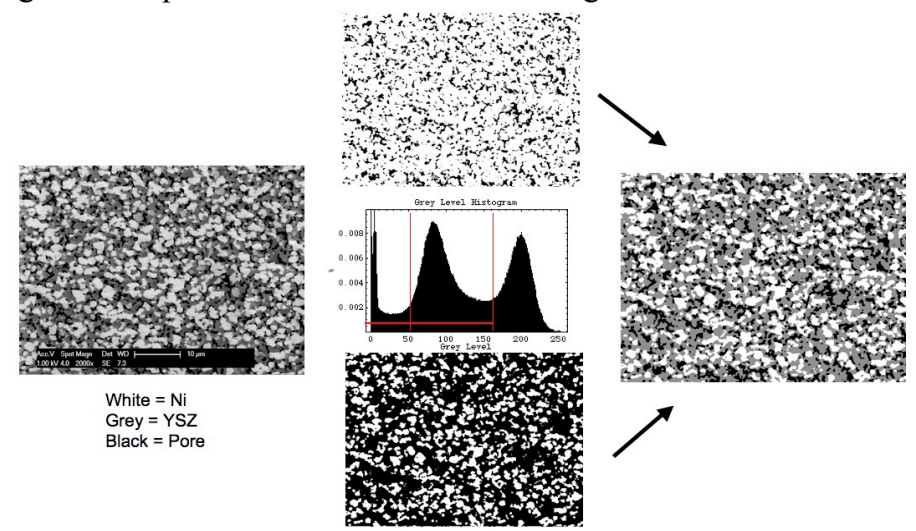

Figure 1. Image treatment steps to separate the three phases of nickel, yttria stabilized zirconia and porosity.

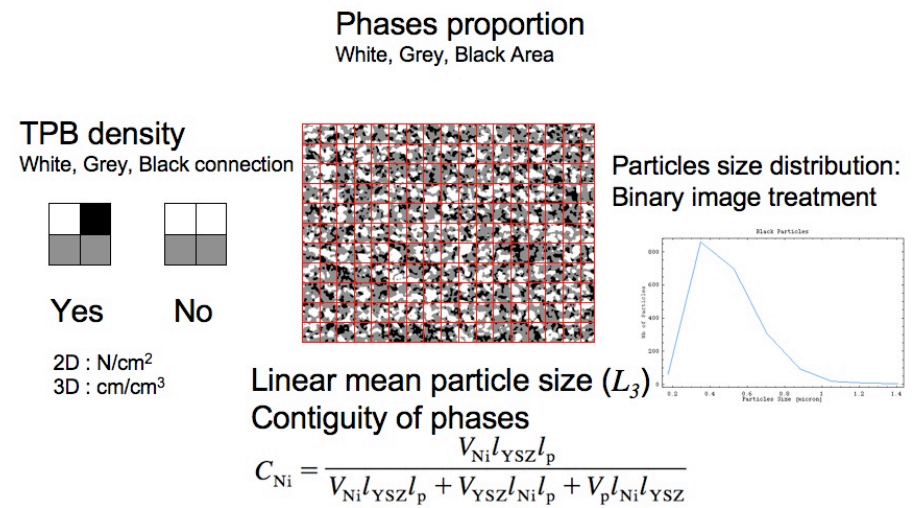

Figure 2. Image analysis of the treated images (see text).

1. D. Simwonis, F. Tietz, and D. Stoever, Solid State Ionics 132 (2000) p. 241.

2. K.R. Lee, S.H. Choi, J. Kim, H.W. Lee, and J.H. Lee, Journal of Power Sources 140 (2005) p. 226.

3. C. Monachon, A. Hessler-Wyser, A. Faes, J. Van herle, and E. Tagliaferri, A quick method for characterizing Nickel-Yttria stabilized Zirconia cermet microstructure by scanning electron microscopy, Journal of the American Ceramic Society, Submitted. 
